\title{
"Development in well-being and social function among Danish hemophilia patients with HIV: a three-wave panel study spanning 24 years"
}

Emilie B. Ingvorsen ${ }^{1}$, Christina Schnohr ${ }^{1 *}$ (D) Terkel Andersen², Lars Lehrmann², Eva Funding ${ }^{3}$, Lone H. Poulsen ${ }^{4}$, Karen B. Holm², Alex L. Laursen ${ }^{5}$, Jan Gerstoft ${ }^{6}$ and Jakob B. Bjorner ${ }^{1,7}$

\begin{abstract}
Background: Between 1975 and 1985 a total of 91 Danish patients with moderate and severe hemophilia (PWH) was infected with HIV constituting a major scandal in the Danish health care system. This study describes the burden of HIV infection among Danish PWH by evaluating changes from 1988 to 2012 in well-being, social function, experiencing stigma and openness about disease among Danish $\mathrm{HIV}^{+} \mathrm{PWH}$.

Methods: Three anonymous surveys were conducted in 1988, 2001 and 2012 targeting all Danish patients with moderate to severe hemophilia. Survey responses were received from 53, 21 and $18 \mathrm{HIV}^{+}$PWH respectively. A matched comparison sample of HIV PWH was identified for each survey-year, using propensity score matching. Differences for each survey-year and trends over time were analyzed using ordinal logistic regression.

Results: In 1988, HIV+ PWH had more psychosomatic symptoms than HIV ${ }^{-}$PWH, but in 2001 life satisfaction was higher among $\mathrm{HIV}^{+}$PWH than among HIV PWH. Tests of differences in trend over time showed larger improvements in life satisfaction among $\mathrm{HIV}^{+}$PWH than HIV PWH, while HIV PWH showed an increase in educational level compared to $\mathrm{HIV}^{+} \mathrm{PWH}$. Analysis restricted to $\mathrm{HIV}^{+} \mathrm{PWH}$ showed an increase in perceived stigmatization.
\end{abstract}

Conclusions: Differences between Danish $\mathrm{HIV}^{+}$and $\mathrm{HIV}^{-} \mathrm{PWH}$ regarding well-being and psychosomatic symptoms seem to have evened out between 1988 and 2012. However, results suggest that $\mathrm{HIV}^{+}$PWH still experience stigmatization and lower levels of education.

Keywords: HIV, Hemophilia, Well-being, Stigma, Social conditions, Employment

\section{Background}

The bleeding disorders Hemophilia A and B, and von Willebrand's Disease are chronic diseases that requires lifelong and costly treatment. These rare and innate diseases are caused by a deficiency of coagulation factor causing longer bleeds when injured than persons with normal coagulation factors. Classification of hemophilia is based on plasma procoagulant levels, and classified as mild, moderate or severe [1]. In spite of being a rare

\footnotetext{
* Correspondence: cwsc@sund.ku.dk

${ }^{1}$ Department of Public Health Section of Social Medicine, University of Copenhagen, Oester Farimagsgade 5, 1014 K Copenhagen, Denmark Full list of author information is available at the end of the article
}

disease, hemophilia has gained a high level of awareness due to the hemophilia scandal. Before heat-treatment of factor products was introduced in 1984, patients with moderate or severe hemophilia (PWH) were infected with both HIV and Hepatitis C worldwide through contaminated blood products used as part of their hemophilia-treatment. In Denmark, a total of $91 \mathrm{PWH}$ were infected with HIV between 1975 and 1985, in some incidents even after the risks of this treatment became known. Historically, patients with hemophilia (PWH) have been burdened with increased risk of bleeds, increased mortality risk, chronic pain and reduced mobility due to hemophilic arthropathy [2]. Improvements of

(c) The Author(s). 2019 Open Access This article is distributed under the terms of the Creative Commons Attribution 4.0 International License (http://creativecommons.org/licenses/by/4.0/), which permits unrestricted use, distribution, and reproduction in any medium, provided you give appropriate credit to the original author(s) and the source, provide a link to the Creative Commons license, and indicate if changes were made. The Creative Commons Public Domain Dedication waiver (http://creativecommons.org/publicdomain/zero/1.0/) applies to the data made available in this article, unless otherwise stated. 
hemophilia treatment - particularly treatment with factor products - during the1970s were accompanied by expectations that PWH would experience reduced mortality, reduced morbidity and increased well-being. However, the HIV epidemic caused a setback for PWH, as HIV infection had devastating impact on the quality of life, quality of care and longevity of PWH [3]. $\mathrm{HIV}^{+}$ PWH were described as one of the major risk groups for AIDS along with intravenous drug users and homosexuals [4]. In the 1980s being infected with HIV was associated with social stigma and both physical and psychological morbidity [5]. At this point in time, there was no effective treatment for HIV and $\mathrm{HIV}^{+}$PWH had a short life expectancy. Many $\mathrm{HIV}^{+} \mathrm{PWH}$ retired early and more than 20 countries, including Denmark, established compensation programs for the patients infected through contaminated blood products $[6,7]$. From the 1980 s and to the 2010s the lives of $\mathrm{HIV}^{+} \mathrm{PWH}$ have undergone improvements in terms of prognosis, disease consequences, and treatment regimens, but also concerning the social stigma around $\mathrm{HIV}^{+}$patients $[8,9]$. However, the consequences of these major improvements for well-being among $\mathrm{HIV}^{+} \mathrm{PWH}$ are not well described [10].

Previous studies have shown varying results when comparing $\mathrm{HIV}^{+} \mathrm{PWH}$ and $\mathrm{HIV}^{-} \mathrm{PWH}$ on quality of life (QoL), well-being, social function, and psychosomatic symptoms. Some studies have found increased psychological distress [11-14], although less so for adolescents being open about their HIV status [15]. Other studies found no significant differences between $\mathrm{HIV}^{+} \mathrm{PWH}$ and $\mathrm{HIV}^{-}$PWH [16-18]. Studies using prospective data regarding the development in well-being and social function are scarce and to the best of our knowledge there have been no recent studies on symptom burden among $\mathrm{HIV}^{+}$PWH.

To evaluate the future needs of PWH and in particular $\mathrm{HIV}^{+} \mathrm{PWH}$, the Danish Hemophilia Society collected survey data on all Danish patients with moderate to severe hemophilia in 1988. These surveys were repeated twice, in 2001 and 2012. Spanning 24 years, the data enable us to study the development in well-being, social function, and stigmatization among $\mathrm{HIV}^{+} \mathrm{PWH}$.

The present study has three aims: 1) To compare wellbeing and social function between Danish $\mathrm{HIV}^{+}$and $\mathrm{HIV}^{-}$ PWH at three time points, 2) To assess the trend in wellbeing and social function over time in $\mathrm{HIV}^{+}$as compared to $\left.\mathrm{HIV}^{-} \mathrm{PWH}, 3\right)$ to assess the trend over time in stigmatization and openness about HIV for $\mathrm{HIV}^{+} \mathrm{PWH}$ (these questions were only asked $\mathrm{HIV}^{+} \mathrm{PWH}$ ). We hypothesized a positive development in well-being and social function, as well as reduced stigmatization due to improved treatment and changes regarding the public attitude and knowledge about HIV.

\section{Methods}

\section{Three-wave panel study}

The Danish Hemophilia Society collected survey data through anonymous questionnaires in 1988, 2001 and 2012. The surveys were developed by the Danish Hemophilia Society. The two Danish hemophilia centers located at Aarhus University Hospital and Copenhagen University Hospital Rigshospitalet, identified all Danish patients with moderate-to-severe hemophilia A or B (factor VIII or IX $\leq 5 \%$ ) or type 3 von Willebrand's disease. The centers also registered HIV status. For 1988, there were $85 \mathrm{HIV}^{+} \mathrm{PWH}$ out of a total of $212 \mathrm{PWH}$ (6 $\mathrm{HIV}^{+}$PWH were diseased before start of the study). In 2001, there were 30 surviving $\mathrm{HIV}^{+} \mathrm{PWH}$ out of 190 PWH. In 2012, there were $27 \mathrm{HIV}^{+} \mathrm{PWH}$ out of 240 PWH. Since no new cases of HIV infection occurred after 1985, the $\mathrm{HIV}^{+}$PWH registered in 1988, 2001 and 2012 are subsamples of the 91 PWH originally infected. The hemophilia centers distributed the 1988 and the 2001 surveys by mail to all identified PWH. In 2012, the survey was administered online with the opportunity to receive a paper version of the questionnaire. In 1988, 53 responses were received from $\mathrm{HIV}^{+} \mathrm{PWH}$ out of a total of 135 responses (response rates 62 and 64\% respectively). In 2001, 21 responses were received from $\mathrm{HIV}^{+}$ PWH out of a total of 164 responses (response rates 70 and 86\%). In 2012, 18 responses were received from $\mathrm{HIV}^{+} \mathrm{PWH}$ out of a total of 166 responses (response rates 67 and 69\%).

\section{Variables}

The study variables are presented in Table 1. Data was self-reported except for yearly factor use; severity of hemophilia; inhibitor; hepatitis B and C; and HIV infection. These variables were assessed by self-report in 1988 and 2012 but from patient charts in 2001. Hemophilia severity was not assessed in 1988. Some of the variables are summarized as two scales regarding joint mobility and psychosomatic symptoms. Joint mobility was assessed by five questions on the range of motion in periods with no bleeds and summed into a scale ranging from 0 (reduced mobility for all types of joint) to 5 (full mobility for all types of joint) [19]. Psychosomatic symptoms were measured by four questions concerning discomforts within the last 2 weeks: headache, anxiety, depression, and fatigue. The responses to the questions were summed into a scale ranging from 0 (no symptoms) to 4 (symptoms within every category). A detailed description of the questionnaires is provided as Additional file 1.

\section{Statistical analyses}

To enable comparisons between $\mathrm{HIV}^{+} \mathrm{PWH}$ and $\mathrm{HIV}^{-}$ $\mathrm{PWH}$, a matched comparison sample was identified for 
Table 1 Description of study variables

\begin{tabular}{|c|c|c|}
\hline & Variable & Definition/Question \\
\hline \multirow[t]{8}{*}{ Background and clinical variables } & Age & Age at January 1st of 1988, 2001 and 2012 \\
\hline & $\begin{array}{l}\text { Number of bleeding episodes } \\
\text { treated with factor }\end{array}$ & $\begin{array}{l}\text { 1988: } 5 \text { response categories } \\
\text { 2001-2012: \# of episodes }\end{array}$ \\
\hline & Yearly factor use $\mathrm{a}^{\mathrm{a}}$ & Units per year \\
\hline & Severity of hemophilia & Moderate; Severe \\
\hline & Inhibitor (ever) ${ }^{a}$ & Never; Current or previous \\
\hline & Hepatitis B or C (ever) ${ }^{a}$ & Never; Current or previous \\
\hline & HIV Infection ${ }^{a}$ & Yes; No \\
\hline & Joint mobility & $\begin{array}{l}\text { Questions on range of motion in periods with no bleeds in the } \\
\text { following joints: hips, knees, ancles, shoulders, and elbows }\end{array}$ \\
\hline \multirow[t]{4}{*}{ Social function } & Education & Highest education completed \\
\hline & Work & Questions on current employment, work hours and social benefits. \\
\hline & Family type & $\begin{array}{l}\text { Living with spouse or partner; Living alone; Other family type } \\
\text { (e.g. living with parents or house sharing) }\end{array}$ \\
\hline & Social activities & $\begin{array}{l}\text { "Do you attend meeting, clubs, or other activities outside work or } \\
\text { school, including sports, evening school or the like?" }\end{array}$ \\
\hline \multirow[t]{4}{*}{ Well-being } & Life satisfaction & $\begin{array}{l}\text { "All in all, how satisfied or dissatisfied are you with your life as it } \\
\text { stands today?" }\end{array}$ \\
\hline & Psychosomatic symptoms & $\begin{array}{l}\text { 'Headache; }{ }^{c} \text { Anxiety, nervousness, unrest; }{ }^{\mathrm{C}} \text { Depressed, in low spirit, } \\
\text { unhappy; }{ }^{\mathrm{C}} \text { Tiredness. }\end{array}$ \\
\hline & Worries & $\begin{array}{l}\text { "Patients with hemophilia have a certain risk of developing } \\
\text { life-threatening bleeds. Do you ever think about that?" }\end{array}$ \\
\hline & Being alone & "Are you ever alone, but want to be together with other people?" \\
\hline \multirow[t]{2}{*}{ Stigma } & Stigma & $\begin{array}{l}\text { "How often have you felt like people look down upon you, avoid } \\
\text { you or in any way react negatively about your HIV positive status?" }\end{array}$ \\
\hline & Openness & "Who knows that you are HIV positive?" \\
\hline
\end{tabular}

${ }_{1} 1988$ and 2012: Self-reported, 2001: Extracted from charts

b 1988: not recorded, 2001: Extracted from charts, 2012: Self-reported

c "Have you, within the last 2 weeks, been bothered with following pain or discomforts."

each of the 3 years, using propensity score matching [20]. Matching variables were age group, yearly factor use and hepatitis infection. Hepatitis infection was not used as matching variable in 1988, since a large proportion of patients in 1988 did not know whether they had been infected. After controlling for age, factor use and hepatitis, other background variables (number of bleeding episodes, presence of inhibitor and joint mobility) were not significantly associated with HIV status and were not used as matching variables. The probability of being HIV infected was calculated from age, factor use, and hepatitis using a logistic regression model. $\mathrm{HIV}^{+}$ PWHs were matched with $\mathrm{HIV}^{-}$PWH of similar risk for HIV infection using 1:1 optimal matching ( $\mathrm{R}$ package MatchIt [21]). Comparisons between $\mathrm{HIV}^{+}$and $\mathrm{HIV}^{-}$ PWH were conducted for each year using ordinal logistic regression. Comparison of $\mathrm{HIV}^{+} \mathrm{PWH}$ and $\mathrm{HIV}^{-}$ PWH showed that the propensity score matching did not provide a perfect match on age and factor use in 1988 and 2012. These variables were therefore included as covariates in subsequent statistical testing. Trend over time was evaluated in a combined data set by including a year times HIV interaction in an ordinal logistic regression model. Comparisons between 1988, 2001 and 2012 were done at group level, since the anonymous questionnaires did not permit tracing of individual patients.

\section{Results}

\section{Treatment related variables and joint mobility}

The proportion of $\mathrm{HIV}^{+}$PWH who had ever experienced Hepatitis infection increased from 54\% in 1988 to $95 \%$ in 2001 (Table 2). Because Hepatitis $C$ was not identified until 1989, the measure from 1988 included Hepatitis B only. For $\mathrm{HIV}^{+}$PWH, frequency of bleeding episodes tended to decrease from 1988 to 2012, but no significant trend was found compared to HIV $^{-}$PWH. In 2001 and 2012, almost all patients had severe hemophilia. The proportion of PWH in the sample having had inhibitor was below $25 \%$ in 1988 and 2001 but 33\% in 2012. Generally, joint mobility declined over time for both $\mathrm{HIV}^{-} \mathrm{PWH}$ and 
Table 2 Data characteristics by survey year and HIV status (\%)

\begin{tabular}{|c|c|c|c|c|c|c|c|}
\hline & & 1988 & & 2001 & & 2012 & \\
\hline & & $\mathrm{HIV}^{+}$ & $\mathrm{HIV}^{-}$ & $\mathrm{HIV}^{+}$ & $\mathrm{HIV}^{-}$ & $\mathrm{HIV}^{+}$ & $\mathrm{HIV}^{-}$ \\
\hline Age distribution & $0-15$ years & 8 & 23 & 0 & 0 & 0 & 0 \\
\hline & $16-24$ years & 26 & 21 & 6 & 6 & 6 & 6 \\
\hline & $25-34$ years & 38 & 25 & 39 & 33 & 0 & 0 \\
\hline & $35-44$ years & 11 & 21 & 39 & 39 & 44 & 33 \\
\hline & $45-54$ years & 17 & 11 & 17 & 22 & 22 & 33 \\
\hline & $55-88$ years & 0 & 0 & 0 & 0 & 28 & 28 \\
\hline & $N$ & (53) & (53) & [18] & [18] & [18] & [18] \\
\hline Factor use (per year) & $0-25.000$ units & 8 & 12 & 0 & 0 & 6 & 6 \\
\hline & $25.001-75.000$ units & 10 & 20 & 20 & 19 & 28 & 22 \\
\hline & $75.001-125.000$ units & 22 & 16 & 35 & 38 & 11 & 22 \\
\hline & $125.001-250.000$ units & 46 & 37 & 35 & 33 & 17 & 22 \\
\hline & $250.001-500.000$ units & 8 & 12 & 10 & 5 & 33 & 22 \\
\hline & 500.001- units & 6 & 2 & 0 & 5 & 6 & 6 \\
\hline & $N$ & (49) & (50) & [21] & {$[20]$} & [18] & [18] \\
\hline Hepatitis B or C & Never & $46^{\mathrm{a}}$ & $63^{\mathrm{a}}$ & 5 & 5 & 6 & 6 \\
\hline & Current or previous & $54^{\mathrm{a}}$ & $37^{\mathrm{a}}$ & 95 & 95 & 94 & 94 \\
\hline & $N$ & (46) & (46) & [21] & {$[21]$} & [18] & [18] \\
\hline Bleeding episodes & No episodes & 6 & 4 & 5 & 0 & 6 & 6 \\
\hline & 1-10 episodes & 34 & 53 & 53 & 50 & 61 & 33 \\
\hline & 11-25 episodes & 30 & 8 & 26 & 15 & 17 & 39 \\
\hline & 26-50 episodes & 19 & 21 & 16 & 25 & 11 & 11 \\
\hline & $51+$ episodes & 11 & 15 & 0 & 10 & 6 & 11 \\
\hline & $N$ & (53) & (53) & {$[20]$} & [19] & [18] & [18] \\
\hline Severity of hemophilia & Severe & - & - & 100 & 100 & 89 & 100 \\
\hline & Moderate & & & 0 & 0 & 11 & 0 \\
\hline & $N$ & & & {$[21]$} & {$[21]$} & [18] & [18] \\
\hline Inhibitor (ever) & Never & 77 & 84 & 81 & 90 & 67 & 67 \\
\hline & Current or previous & 23 & 16 & 19 & 10 & 33 & 33 \\
\hline & $N$ & $(50)$ & $(52)$ & [21] & {$[21]$} & [18] & [18] \\
\hline Joint mobility & 0 & 13 & 9 & 24 & 14 & 17 & 22 \\
\hline & 1 & 17 & 17 & 10 & 5 & 6 & 22 \\
\hline & 2 & 25 & 9 & 19 & 24 & 44 & 17 \\
\hline & 3 & 15 & 21 & 10 & 24 & 17 & 22 \\
\hline & 4 & 17 & 13 & 38 & 24 & 11 & 11 \\
\hline & 5 & 12 & 30 & 0 & 10 & 6 & 6 \\
\hline & $N$ & & & & & & \\
\hline
\end{tabular}

anly HBV

$\mathrm{HIV}^{+}$PWH with only one patient from each group having full joint mobility (level 5) in 2012.

\section{Social function and well-being}

Table 3 shows tests of differences between $\mathrm{HIV}^{+}$and $\mathrm{HIV}^{-} \mathrm{PWH}$ for each of the 3 years and tests for trends over time for $\mathrm{HIV}^{+} \mathrm{PWH}$ compared to $\mathrm{HIV}^{-} \mathrm{PWH}$.
Figure 1 shows descriptive information for these variables. As shown in Table 3, three comparisons of $\mathrm{HIV}^{+}$ and $\mathrm{HIV}^{-} \mathrm{PWH}$ were statistically significant at a $5 \%$ level; psychosomatic symptoms, life satisfaction and level of education. In 1988, $\mathrm{HIV}^{+} \mathrm{PWH}$ had more psychosomatic symptoms than $\mathrm{HIV}^{-}(p=0.026$, Table 3 , Fig. 1$)$. In 2001, life satisfaction was higher among $\mathrm{HIV}^{+}$ 
Table 3 P-values of trends statistically significant trends in italic

\begin{tabular}{lllll}
\hline & \multicolumn{3}{l}{$\mathrm{HIV}^{+} / \mathrm{HIV}^{-\mathrm{a}}$} & $\begin{array}{l}\text { Trends } \\
\left(\mathrm{HIV}^{+} /\right. \\
\left.\mathrm{HIV}^{\mathrm{b}}\right)^{\mathrm{b}}\end{array}$ \\
\cline { 2 - 4 } Education & 0,717 & 0,622 & 0,015 & 0,024 \\
Work & 0.075 & 0.534 & 0.328 & 0.113 \\
Social activities & 0.752 & 0.679 & 0.901 & 0.884 \\
Family type & 0,333 & 0,753 & 0,459 & 0,383 \\
Life satisfaction & 0.179 & 0.049 & 0.655 & 0.046 \\
Psychosomatic symptoms & 0.026 & 0.552 & 0.395 & 0.173 \\
Worries & 0.996 & 0.169 & 0.649 & 0.379 \\
Being Alone & 0.535 & 0.166 & 0.561 & 0.121 \\
\hline
\end{tabular}

${ }^{a}$ Comparison between $\mathrm{HIV}^{+}$and $\mathrm{HIV}^{-}$for each year

${ }^{\mathrm{b}}$ Trend over time for $\mathrm{HIV}^{+}$compared to HIV

compared to $\mathrm{HIV}^{-} \mathrm{PWH}(p=0,049$, Table 3). In 2012, the level of education was higher among HIV $^{-}$compared to $\mathrm{HIV}^{+}$PWH ( $p=0,015$, Table 3$)$. Tests of differences in trend over time found two significant results: the trend in life satisfaction was more positive for $\mathrm{HIV}^{+}$ PWH compared to $\mathrm{HIV}^{-} \mathrm{PWH}(p=0,046$, Table 3$)$. Across years, $\mathrm{HIV}^{-}$PWH attained higher levels of education than $\mathrm{HIV}^{+}$PWH $(p=0,024$, Table 3).

While no other statistically significant HIV-related differences were found, some trends in the data are worth noticing. While the proportion of $\mathrm{HIV}^{+} \mathrm{PWH}$ with a regular full-time job was steady throughout the 24 years (range 33-38\%), the proportion of $\mathrm{HIV}^{-} \mathrm{PWH}$ with a regular full-time job increased from 15 to $56 \%$. A decrease was seen in social activities, but this decrease was seen for both $\mathrm{HIV}^{+}$PWH and $\mathrm{HIV}^{-}$PWH. Similarly, an increase was seen in the number of both $\mathrm{HIV}^{+} \mathrm{PWH}$ and $\mathrm{HIV}^{-}$PWH living with partner or spouse, more prominently among $\mathrm{HIV}^{-} \mathrm{PWH}$.

\section{Stigmatization and openness about HIV}

Figures 2 and 3 show the analyses of the experienced stigmatization and openness towards spouse/partner, children, families and colleagues. There was a significant increase in experienced stigmatization among $\mathrm{HIV}^{+}$ PWH from 1988 to 2012 ( $p=0,006$, Fig. 2), with larger proportions of $\mathrm{HIV}^{+} \mathrm{PWH}$ in 2012 that had experienced stigmatization many times or occasionally.

While no changes over time regarding openness were statistically significant, the figures suggest some trends: The proportion of $\mathrm{HIV}^{+}$PWH being open about their HIV status to spouse/partner and children saw an overall increase from 1988 to 2012 (Fig. 3). In 2012 24\% of $\mathrm{HIV}^{+} \mathrm{PWH}$ indicated that their children did not know about their HIV status. Openness about HIV status to other family increased, whereas openness towards colleagues decreased.

\section{Discussion}

This study found a higher burden of psychosomatic symptoms such as anxiety, headache, tiredness and depression among $\mathrm{HIV}^{+} \mathrm{PWH}$ compared to $\mathrm{HIV}^{-} \mathrm{PWH}$ in 1988. We also found higher levels of life satisfaction among $\mathrm{HIV}^{+} \mathrm{PWH}$ in 2001 compared to $\mathrm{HIV}^{-}$, and a significantly more positive trend over time in life satisfaction among $\mathrm{HIV}^{+}$compared to $\mathrm{HIV}^{-}$PWH. In 2012, a higher level of education was seen among $\mathrm{HIV}^{-} \mathrm{PWH}$ compared to $\mathrm{HIV}^{+} \mathrm{PWH}$ and a significant trend over time towards higher education for $\mathrm{HIV}^{-} \mathrm{PWH}$. No differences between $\mathrm{HIV}^{+}$and $\mathrm{HIV}^{-} \mathrm{PWH}$ in social activities, feelings of loneliness, or worries about bleeding were found. Finally, in analyses restricted to $\mathrm{HIV}^{+} \mathrm{PWH}$, we found an increase in perceived stigmatization from 1988 to 2012.

Our findings on experienced stigma contradicted our hypotheses and were inconsistent with previous studies on stigma among $\mathrm{HIV}^{+}$patients in general [9]. There are several possible explanations for these findings. A qualitative study from 2015 found HIV-related stigma within health contexts to be a broad and complex phenomenon [8]. Our questions may have been too simple to reflect this complexity. We asked about ever having experienced stigmatization, and the results from 2001 and 2012 may therefore reflect accumulation of experience through many years of being HIV infected. The fact that $\mathrm{HIV}^{+} \mathrm{PWH}$ still recalls experience of stigmatization may reflect a persistent stigma associated with HIV infection and points to an issue of importance to $\mathrm{HIV}^{+} \mathrm{PWH}$.

We found weak and statistically insignificant trends towards greater openness about HIV status. A study from 2002 found that openness about HIV status among adolescents was positively associated with both social support, self-competence and decreased problem behavior [15]. The direction of an association between HIV openness and support is unclear. It is possible that openness about HIV induce sympathy and social support. On the other hand, $\mathrm{HIV}^{+} \mathrm{PWH}$ may only choose to be open about HIV if they trust the environment to be supportive.

Our results regarding increased psychosomatic symptoms in 1988 are in line with a 1990 US study [11] and a 1992 Canadian study [5] finding elevated scores of depression and anxiety among $\mathrm{HIV}^{+} \mathrm{PWH}$. In relation to our findings on increased well-being among $\mathrm{HIV}^{+} \mathrm{PWH}$ in 2001, results from other studies are mixed. Some studies show low satisfaction [5, 12, 13] and QoL [14]. An Italian study from 1995 [18] found worse psychological problems among $21 \mathrm{HIV}^{-} \mathrm{PWH}$ than among 24 $\mathrm{HIV}^{+}$PWH and a study from 1999 found no association between HIV-status and health related QoL among individuals with severe hemophilia [16]. Qualitative data suggest that $\mathrm{HIV}^{+} \mathrm{PWH}$ suffer from a psychological and 


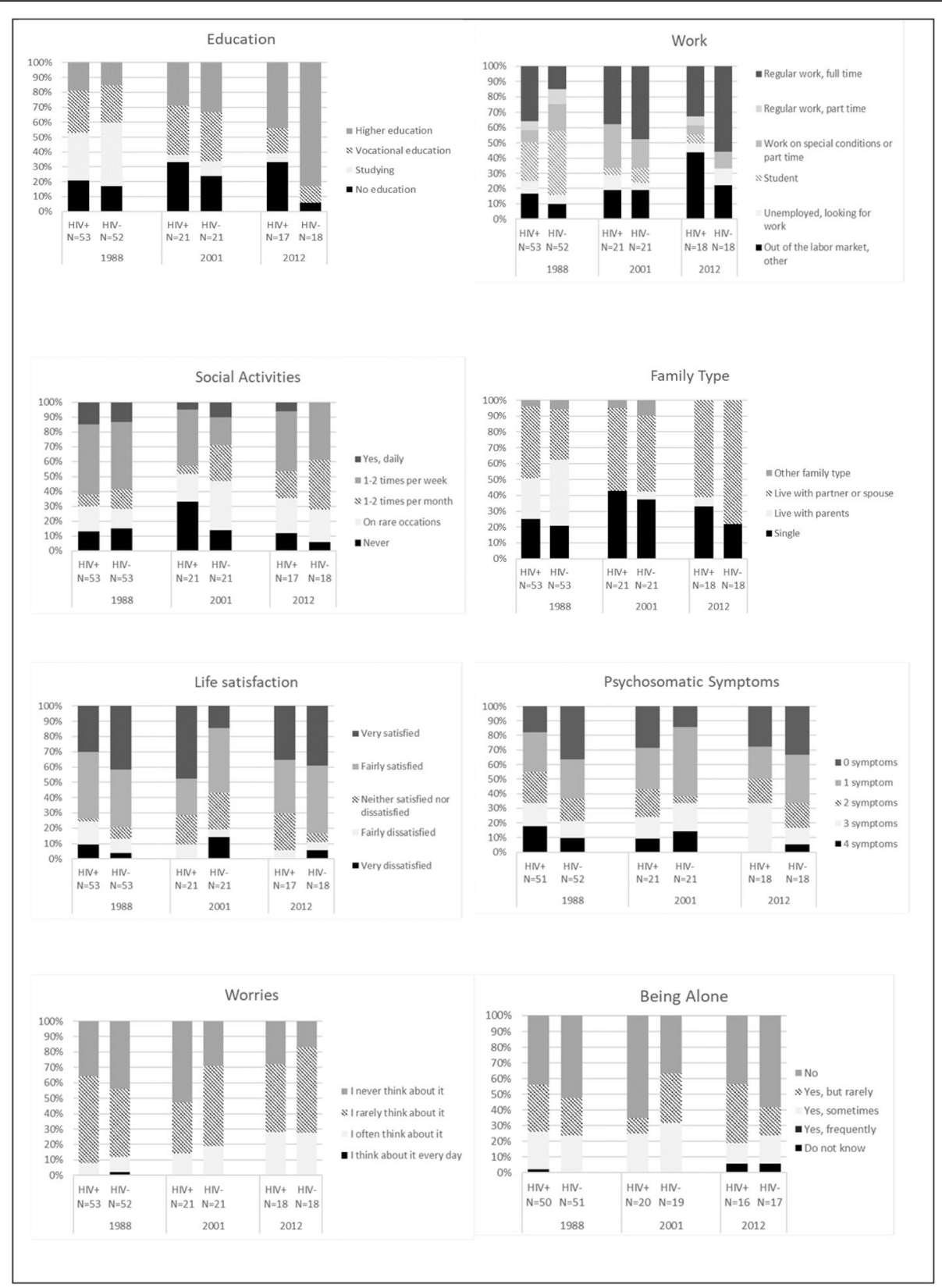

Fig. 1 Descriptive information on variables

physiological burden of HIV [22], as expressed by one Danish $\mathrm{HIV}^{+}$PWH (authors translation) [23]:

I still don't dare to look far ahead into the future. For many years, my life revolved on getting used to dying soon, and now one suddenly has to live. In certain contexts, life is harder than death when you have grown up hand in hand with death.

All results must also be interpreted in the light of scientific and social developments regarding hemophilia and HIV/AIDS over the 24-year span. In 1988, there was no curative treatment for HIV, thus $\mathrm{HIV}^{+}$PWH were influenced by numerous uncertainties on their prognosis. Following the introduction of Highly Active Antiretroviral Treatment (HAART) in the late 1990s the prognosis for $\mathrm{HIV}^{+} \mathrm{PWH}$ improved considerably which may explain our results showing increased life satisfaction among $\mathrm{HIV}^{+} \mathrm{PWH}$ in 2001. The somewhat similar level of well-being between $\mathrm{HIV}^{+} \mathrm{PWH}$ and $\mathrm{HIV}^{-} \mathrm{PWH}$ in 2012 might be due to the two groups' comparable disabilities and possibilities in life.

The differences between $\mathrm{HIV}^{-}$and $\mathrm{HIV}^{+}$PWH regarding educational level in 2012 may indicate that being co- 


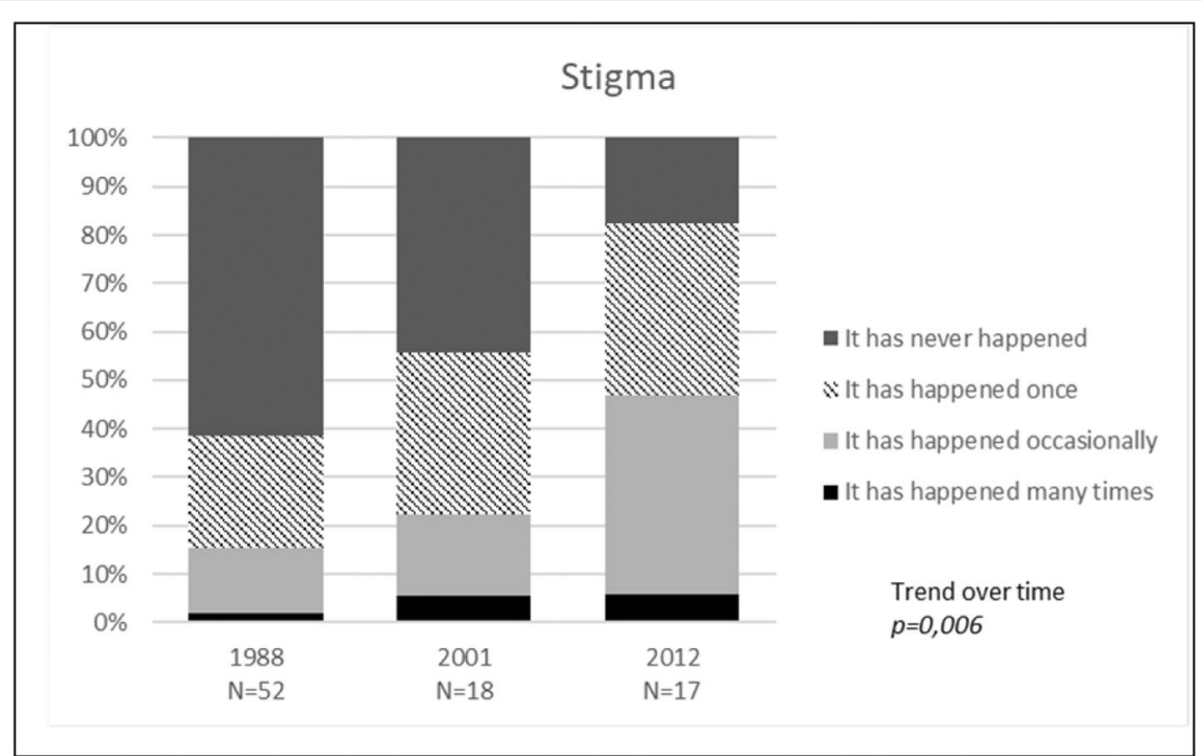

Fig. 2 Perceived stigmatization of HIV status among HIV-positive PWH

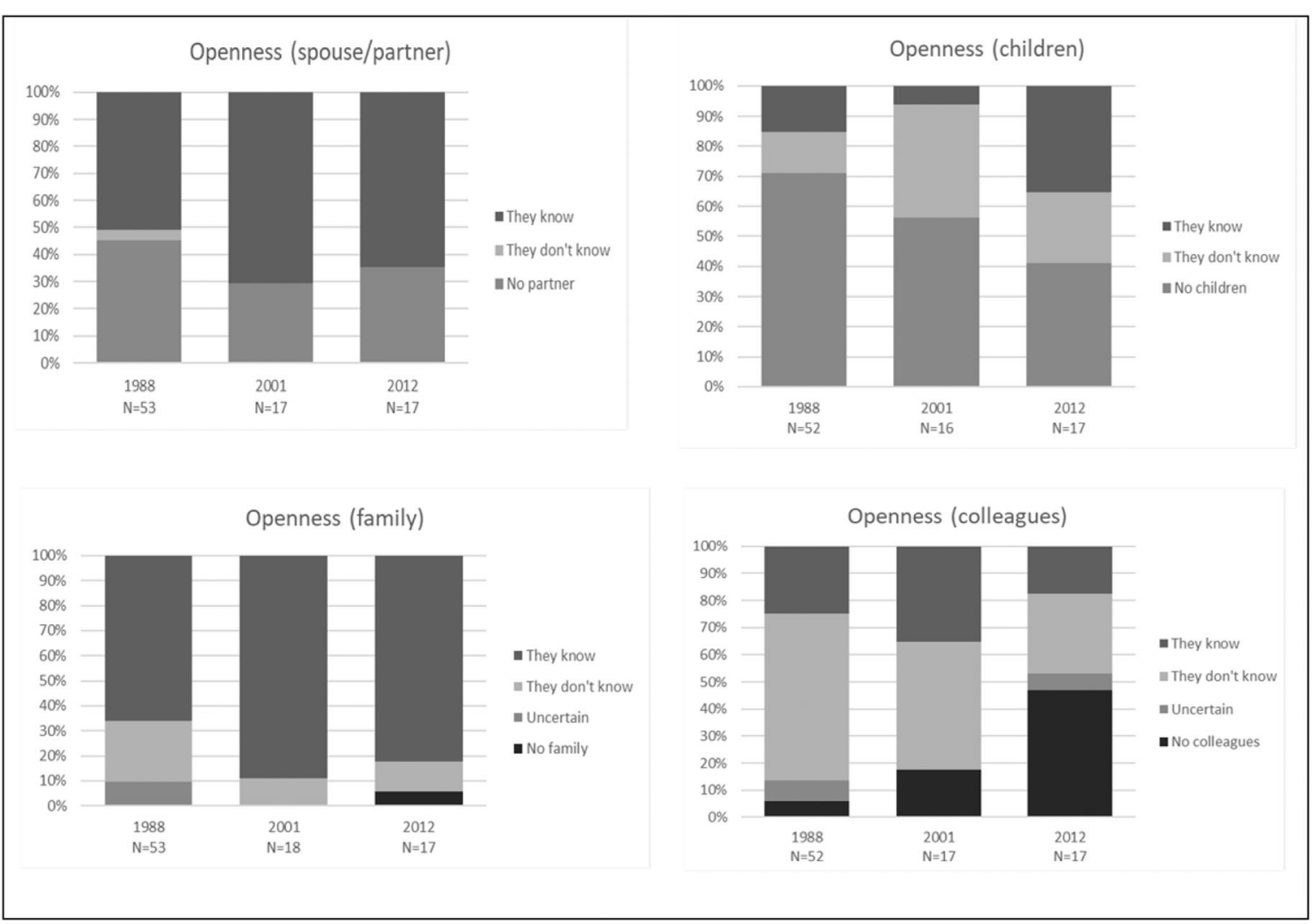

Fig. 3 Openness about disease 
infected with HIV has been a barrier for completing further education. The explanations for this barrier may be complex. $\mathrm{HIV}^{+} \mathrm{PWH}$, who were in the educational system in 1988 may have dropped out or decided not to pursue higher education in light of their perceived low life expectancy. In subsequent years where life expectancy dramatically improved for $\mathrm{HIV}^{+} \mathrm{PWH}$, they may have experienced 'survivors guilt' [24] and felt undeserved of pursuing opportunities such as higher education, despite their life expectancy being the same as for $\mathrm{HIV}^{-} \mathrm{PWH}$.

In general, our original hypotheses on differences regarding well-being and social function between $\mathrm{HIV}^{+} \mathrm{PWH}$ and $\mathrm{HIV}^{-} \mathrm{PWH}$ were only partly met. While qualitative studies from 1985 to 1991 describe severe psychological impact of HIV-infection among PWH $[5,11]$, several other authors have found surprisingly small differences between $\mathrm{HIV}^{+}$ PWH and HIV ${ }^{-}$PWH $[14,16-18]$. Similarities between $\mathrm{HIV}^{+} \mathrm{PWH}$ and $\mathrm{HIV}^{-} \mathrm{PWH}$ may have several explanations.

First, results may be biased by non-response from the $\mathrm{HIV}^{+} \mathrm{PWH}$ with the largest impact of HIV infection, causing us to underestimate the impact of HIV.

Second, from 1988 to 2001 mortality was high among $\mathrm{HIV}^{+}$PWH and may have been particularly high for the $\mathrm{HIV}^{+} \mathrm{PWH}$ with worst health and lowest quality of life.

Third, even when responding, PWH may underreport symptoms and problems. Qualitative studies have found that some PWH downplay their symptoms and problems as a coping mechanism [25].

Fourth, lack of statistical power due to small sample size may cause us to overlook differences in well-being that are important to patients.

Fifth, Danish $\mathrm{HIV}^{+}$PWH received an economic compensation for having been infected with HIV [26] and psychological and social counseling services for $\mathrm{HIV}^{+}$ PWH were established by the Danish Hemophilia Society. The compensations and opportunities for support may have reduced the psychological consequences of HIV infection.

Sixth, in light of the multiple burdens and health risks experienced by PWH, the incremental impact of HIV infection after the introduction of HAART might have been smaller than anticipated by outsiders. A limitation in understanding the differences between $\mathrm{HIV}^{+} \mathrm{PWH}$ and $\mathrm{HIV}^{-} \mathrm{PWH}$ is that we do not have person-level information about HIV-related comorbidities or antiretrovival treatment. On population level we know that HAART was offered to all $\mathrm{HIV}^{+}$PWH in 2001 and 2012 and accepted by nearly all.

Finally, analyses of openness and perceived stigma were carried out in the $\mathrm{HIV}^{+}$group only. The average age of $\mathrm{HIV}^{+}$PWH increased from 1988 to 2012, which may have biased the results, if perceptions of stigma vary between the young and the old.
There are several strengths to be noted in the current study. First, a large proportion of the Danish $\mathrm{HIV}^{+} \mathrm{PWH}$ from 1988 to 2012 were included, providing knowledge from the group of Danish patients. Second, the information was obtained over a long time span providing more extensive insight than previous studies. Third, propensity score matching enabled us to identify the best possible comparison groups of $\mathrm{HIV}^{-} \mathrm{PWH}$.

\section{Conclusion}

The differences between Danish $\mathrm{HIV}^{+}$and $\mathrm{HIV}^{-} \mathrm{PWH}$ regarding both well-being and psychosomatic symptoms seem to have evened out from 1988 to 2012, even though there are still differences regarding employment and education. Despite great improvements concerning treatment, public attitude and knowledge about HIV, $\mathrm{HIV}^{+}$PWH still experience challenges. The health risks and the psychosomatic burdens associated with both hemophilia and HIV should be held in mind when reviewing the need for social, psychological and financial support in this patient group.

\section{Supplementary information}

Supplementary information accompanies this paper at https://doi.org/10. 1186/s12889-019-8062-9.

Additional file 1. Description of study questionnaire.

\section{Abbreviations}

HIV: Human Immunodeficiency Virus; PWH: Patients with hemophilia; QoL: Quality of life

\section{Acknowledgements}

The authors want to thank the nurses in the hemophilia centers and the staff at the Danish Hemophilia Society for sending out and receiving letters from all participants, Susan Cowan and Tyra Grove Krause, Statens Serum Institut, for data on vital status of Danish Hemophilia Patients, and Annegrethe Hansen, Section of Social Medicine, University of Copenhagen, for comments on a previous version of this paper.

\section{Authors' contributions}

The process of producing the manuscript was by initiative from EBI, CS and $J B B$ followed by an iterative production from EBI, CS, JBB, TA, LL, EF, LHP, $\mathrm{KBH}, \mathrm{ALL}$ and JG; all authors have made substantial contributions to the conception and design of the work, JBB have performed the analysis in collaboration with $\mathrm{EBI}$ and $\mathrm{CS}, \mathrm{JBB}, \mathrm{EBI}$ and $\mathrm{CS}$ have drafted the main part of the work and all authors have revised, commented and approved the submitted version. All authors have agreed to be personally accountable for the work and questions related to the accuracy and integrity of any part of the work.

\section{Funding}

This project has been supported by an unrestricted grant from Gilead Sciences to the position as research assistant for EBI to write the manuscript. Gilead had no influence on data collection, analysis, or interpretation.

\section{Availability of data and materials}

The datasets generated and/or analyzed during the current study are not publicly available due the protection of personal information among the group of anonymous participants. Tabled data are available from JBB on reasonable request. 


\section{Ethics approval and consent to participate}

The 1988 study was approved by the Danish Institutional Review Board. Subsequently, Danish Law specified that questionnaire studies did not require ethical approval [27], so the 2001 and 2012 surveys did not require and could not obtain renewed approval. The questionnaires were accompanied by information regarding the participation being voluntary and having no impact on treatment. For children, parents filled out the questionnaire together with the participant or on behalf of the participant. Informed consent was given by returning a completed version of the questionnaire to the Danish Hemophilia Society, thus written consent was not applicable. For children, informed consent was provided by parents when participating. The Danish National Committee on Health Research Ethics approve consent in this form.

\section{Consent for publication}

Not applicable.

\section{Competing interests}

TA received a speaker fee at Novo-Nordisk Workshop in 2017. The other authors stated that they had no interest which might be perceived as posing a conflict or bias.

\section{Author details}

${ }^{1}$ Department of Public Health Section of Social Medicine, University of Copenhagen, Oester Farimagsgade 5, 1014 K Copenhagen, Denmark. ${ }^{2}$ The Danish Haemophilia Society, Copenhagen, Denmark. ${ }^{3}$ Department of Hematology Rigshospitalet, Copenhagen, Denmark. ${ }^{4}$ Aarhus University Hospital, Centre for thrombosis and hemostasis, Aarhus, Denmark. ${ }^{5}$ Department of Infectious Diseases Aarhus, Aarhus University Hospital, Aarhus, Denmark. ${ }^{6}$ Department of Infectious Diseases, Rigshospitalet, Copenhagen $\varnothing$, Denmark. ${ }^{7}$ Optum Patient Insights, Johnston, RI, USA.

Received: 13 June 2019 Accepted: 11 December 2019

Published online: 19 December 2019

\section{References}

1. White GC 2nd, Rosendaal F, Aledort LM, Lusher JM, Rothschild C, Ingerslev J. Definitions in hemophilia. Recommendation of the scientific subcommittee on factor VIII and factor IX of the scientific and standardization committee of the International Society on Thrombosis and Haemostasis. Thromb Haemost. 2001;85(3):560.

2. World Federation of Hemophilia. Symptoms and diagnosis 2012 [Available from: https://www.wfh.org/en/page.aspx?pid=640.

3. Evatt B. Infectious disease in the blood supply and the public health response. Semin Hematol. 2006;43(2 Suppl 3):S4-9.

4. Wilkie PA, Markova I, Naji SA, Forbes CD. Daily living problems of people with haemophilia and HIV infection: implications for counselling. Int J Rehabil Res. 1990;13(1):15-25.

5. Catalan J, Klimes I, Bond A, Day A, Garrod A, Rizza C. The psychosocial impact of HIV infection in men with haemophilia: controlled investigation and factors associated with psychiatric morbidity. J Psychosom Res. 1992; 36(5):409-16.

6. Weinberg PD, Hounshell J, Sherman LA, Godwin J, Ali S, Tomori C, et al. Legal, financial, and public health consequences of HIV contamination of blood and blood products in the 1980s and 1990s. Ann Intern Med. 2002; 136(4):312-9.

7. The Danish Haemophilia Society. The hemophilia lawsuit [Blødersagen] 2018 [Available from: https://www.bloderforeningen.dk/danmarksbloderforening/historie/blodersagen.

8. Chambers LA, Rueda S, Baker DN, Wilson MG, Deutsch R, Raeifar E, et al. Stigma, HIV and health: a qualitative synthesis. BMC Public Health. 2015;15:848

9. Stangl AL, Lloyd JK, Brady LM, Holland CE, Baral S. A systematic review of interventions to reduce HIV-related stigma and discrimination from 2002 to 2013: how far have we come? J Int AIDS Soc. 2013;16(3 Suppl 2):18734.

10. Ferreira AA, Leite IC, Bustamante-Teixeira MT, Correa CS, da Cruz DT, Rodrigues Dde O, et al. Health-related quality of life in hemophilia: results of the hemophilia-specific quality of life index (Haem-a-Qol) at a Brazilian blood center. Rev Bras Hematol Hemoter. 2013;35(5):314-8.
11. Dew MA, Ragni MV, Nimorwicz P. Infection with human immunodeficiency virus and vulnerability to psychiatric distress. A study of men with hemophilia. Arch Gen Psychiatry. 1990;47(8):737-44.

12. Barr RD, Saleh M, Furlong W, Horsman J, Sek J, Pai M, et al. Health status and health-related quality of life associated with hemophilia. Am J Hematol. 2002;71(3):152-60.

13. Tanaka S, Hachisuka K, Okazaki T, Shirahata A, Ogata H. Health status and satisfaction of asymptomatic HIV-positive haemophiliacs in Kyushu, Japan. Haemophilia. 1999;5(1):56-62.

14. Djulbegovic B, Goldsmith G, Vaughn D, Birkimer J, Marasa M, Joseph G, et al. Comparison of the quality of life between HIV-positive haemophilia patients and HIV-negative haemophilia patients. Haemophilia. 1996;2(3):166-72.

15. Battles HB, Wiener LS. From adolescence through young adulthood: psychosocial adjustment associated with long-term survival of HIV. J Adolesc Health. 2002;30(3):161-8

16. Miners AH, Sabin CA, Tolley KH, Jenkinson C, Kind P, Lee CA. Assessing health-related quality-of-life in individuals with haemophilia. Haemophilia. 1999;5(6):378-85.

17. Pasqual Marsettin E, Ciavarella N, Lobaccaro C, Ghirardini A, Puopolo M, Cultraro D, et al. Knowledge of HIV/AIDS and emotional adjustment in a cohort of men with haemophilia and HIV infection: final report. Haemophilia. 1998:4(6):820-5.

18. Marsettin EP, Ciavarella N, Lobaccaro C, Ghirardini A, Bellocco R, Schinaia N. Psychological status of men with haemophilia and HIV infection: two-year follow-up. Haemophilia. 1995; (4):255-61.

19. Schnohr C, Bacher $T$, Andersen $T$, Lehrmann L, Funding $E$, Poulsen $L H$, et al. Joint mobility and physical function of Danish hemophilia patients: a threewave panel study spanning 24 years. Acta Haematol. 2018;140(4):240-6.

20. Stuart EA. Matching methods for causal inference: a review and a look forward. Stat Sci. 2010;25(1):1-21.

21. Ho DE, Imai K, King G, Stuart EA. Matching as nonparametric preprocessing for reducing model dependence in parametric causal inference. Polit Anal. 2007;15(3):199-236.

22. Westersø RS. 91 Danish hemophiliacs were infected with HIV, 26 survived [91 danske blødere blev smittet med HIV: 26 overlevede]: B.T. 2014 [Available from: https://www.bt.dk/danmark/91-danske-bloedere-blevsmittet-med-hiv-26-overlevede.

23. Pagter LK. Now you suddenly have to live [Nu skal man pludselig til at leve]. Bloedernyt. 2008:8-9. [Available from: https://www.bloderforeningen.dk/ sites/default/files/mediearkiv/pdf/Bl\%C3\%B8derNyt\%204\%202008\%2 ONETversion.pdf].

24. Hutson SP, Hall JM, Pack FL. Survivor guilt: analyzing the concept and its contexts. ANS Adv Nurs Sci. 2015;38(1):20-33.

25. Brodin E, Sunnerhagen KS, Baghaei F, Tornbom M. Persons with Haemophilia in Sweden- experiences and strategies in everyday life. A Single Centre Study. PLoS One. 2015;10(10):e0139690.

26. Retsinformation.dk. Law on the hemophilia compensation fund [Lov om Blødererstatningsfonden] [Updated June 6, 2018. Available from: https:// www.retsinformation.dk/forms/r0710.aspx?id=46951.

27. Retsinformation.dk. Law on the Scientific Ethical Treatment of Health Sciences Research Projects [Lov om videnskabsetisk behandling af sundhedsvidenskabelige forskningsprojekter] [Updated June 6, 2018. Available from: https://www.retsinformation.dk/forms/R0710.aspx?id=192671.

\section{Publisher's Note}

Springer Nature remains neutral with regard to jurisdictional claims in published maps and institutional affiliations.

\section{Ready to submit your research? Choose BMC and benefit from}

- fast, convenient online submission

- thorough peer review by experienced researchers in your field

- rapid publication on acceptance

- support for research data, including large and complex data types

- gold Open Access which fosters wider collaboration and increased citations

- maximum visibility for your research: over $100 \mathrm{M}$ website views per year

At BMC, research is always in progress.

Learn more biomedcentral.com/submissions 